\title{
Associated Factors with Diet and Exercise Compliance and Smoking Habits in Diabetic Patients of Punjab, Pakistan
}

\author{
Ali H. Gillani 1,2,3,4, Abu B. Ahmed ${ }^{5}$, Sadia Bashir ${ }^{6}$, Mohamed I. M. Ibrahim ${ }^{7}$ and Yu Fang Fa, $^{1,2,4}$ \\ ${ }^{1}$ Department of Pharmacy Administration and Clinical Pharmacy, School of Pharmacy Xi'an Jiaotong University, Shaanxi, China; ${ }^{2}$ Center for Drug \\ Safety and Policy Research, Xian Jiaotong University, Xi'an, Shaanxi, China; ${ }^{3} T h e$ Global Health Institute, Xian Jiaotong University, Xi'an, Shaanxi, \\ China; ${ }^{4}$ Shaanxi Centre for Health Reform and Development Research, Shaanxi, China; ${ }^{5}$ Department of Pharmacy and Alternative Medicine, Islamia \\ University, Bahawalpur, Punjab, Pakistan; ${ }^{6}$ Department of Pathology, Quaid e Azam Medical College, Bahawalpur, Punjab, Pakistan; ${ }^{7}$ Department of \\ Social \& Administrative Pharmacy, Clinical Pharmacy and Practice Section, College of Pharmacy, Qatar University, Qatar
}

\begin{abstract}
Introduction: The prime focus of this study is the evaluation of the factors associated with diet and exercise compliance and smoking prevalence among the diabetic population in the Southern Punjab in Pakistan. Materials and Methods: Research was carried out in between December 2015 and March 2016 employing the descriptive, cross-sectional design using a paper-based questionnaire. We undertook systemic sampling procedure and choose every $3^{\text {rd }}$ diabetic patients visiting three public hospitals and three private clinics. Cholesterol and blood glucose levels were monitored during the survey. Data were summarized by descriptive statistics. A 3-day recall method for macronutrient was used to assess the dietary history and diet compliance. At least a 30 min rigorous walk per day or a total of $2.5 \mathrm{~h}$ per week was a requirement for exercise compliance. Those patients who admitted smoking tobacco in the past 12 months were taken as current smokers. Statistical analysis was done using SPSS Version 18.0 (SPSS, Chicago, IL, USA). Results: Diet and exercise compliance and smoking prevalence were shown by $36.5 \%, 58.8 \%$, and $15.4 \%$ patients, respectively. Patients feeling easy with a diet plan [adjusted odds ratio $(A O R)=20.874,95 \%$ confidence interval $(C l)=9.876,44.119]$ and patients who were aware which diet was harmful to them $(A O R=7.106,95 \% \mathrm{Cl}=3.529,14.309)$ were significantly associated with dietary compliance. Age $(A O R=0.971,95 \%$ $\mathrm{Cl}=0.951,0.991)$ and patients who believe that exercise will lead to weight loss ( $A O R=4.978,95 \% \mathrm{Cl}=2.725,9.093$ ) were independently associated factors of exercise compliance. Gender was only an associated variable with smoking $(A O R=0.127,95 \% \mathrm{Cl}=0.048,0.331)$. Conclusion: Determinant factors of diet compliance were feeling ease with diet plan and knowledge about a harmful diet. Age and belief that exercise will lead to weight loss are significant factors to adhere to exercise compliance. Male gender significantly indulges in more smoking practices than females.
\end{abstract}

Key words: Diabetes. Compliance. Exercise. Diet. Smoking.

\section{Introduction}

There is an inevitable increase in the diabetic population around the globe as the number has risen from
366 million in 2011 to 415 million in $2014^{1-3}$. The diabetic population is expected to reach 642 million in 2040 in the world ${ }^{3}$. Low- and middle-income nations encounter $80 \%$ of the disease burden with a high proportion of

\section{Correspondence:}

Yu Fang

E-mail: yufang@mail.xjtu.edu.cn
Date of reception: 03-09-2017

Date of acceptance: 09-11-2017

DOI: 10.24875/RMU.M18000003
Available online: 30-05-2018 Medicina Universitaria. 2018;20(1):4-12 www.medicinauniversitaria.org

作 2017 Universidad Autónoma de Nuevo Leon. Published by Permanyer México SA de CV. This is an open access article under the CC BY-NC-ND license (http://creativecommons.org/licenses/by-nc-nd/4.0/). 
type 2 diabetes mellitus (DM)2. Pakistan currently ranked $6^{\text {th }}$ around the globe in diabetes cases and prevalence was found to be $6.9 \%$, and in 2020 , it will become the $4^{\text {th }}$ leading country in diabetic population ${ }^{4,5}$. DMs pertaining drastic and life-threatening nature is one of the foremost causes of morbidity and mortality. DM is estimated to become the $7^{\text {th }}$ leading cause of death by $2030^{6}$.

Proper diet management is proved to be a landmark in diabetes care which is supported by healthy eating routines in context of cultural, social, and psychological influence on food ${ }^{7}$. To achieve the desired therapeutic outcome and disease management, a balance should be established among eating, exercise, and medication therapy ${ }^{8}$. The term dietary practice is referred as patient's preference regarding food consumption that is based on proper dietary education with an emphasis on lower fat, higher fiber, and lower sodium food intake $^{9}$. However, the dilemma is that most of the diabetic population is unable to identify the optimal quantity and quality of food that they need to consume to have appropriate control on blood glucose level (BGL) ${ }^{10}$. A significant and pivotal role is played by physical activity in diabetes management ${ }^{11,12}$. Exercise role in diabetes management is further proved by the study in which 150 min walk per week decreases the diabetes incidence in non-diabetics with elevated plasma glucose ${ }^{13}$. Active or passive smoking is proved to be a hazard factor for diabetes ${ }^{14}$. Smoking has a direct and strong relationship with diabetes, and all kind of tobacco use is associated with high morbidity and mortality ${ }^{15,16}$. According to the previous studies in Pakistan, the prevalence of active smoking was $13 \%$ and passive smoking was $40 \%{ }^{17}$.

Exercise and diet compliance as a disease management tool can be well demonstrated by the Finnish Diabetes Prevention Study, according to which there is $58 \%$ reduction in the incidence of diabetes due to intensive diabetes care including exercise habits and diet adjustments ${ }^{18}$. Moreover, dietary and lifestyle changes play a crucial part in diabetes care. Diabetes imparts psychological, physical, economical, and social burdens on patients and society. Hence, prevention by lifestyle modification is a foremost strategy to manage it. According to the National Health Survey of Pakistan, smoking prevalence was found to be $21.6 \%$, yet the research gap exists to evaluate the prevalence of smoking among diabetics in Southern Punjab, Pakistan. Thus, this study aimed to assess the factors associated with diet, exercise compliance, and smoking among diabetic patients (type 1 and type 2 diabetic patients) in Southern Punjab, Pakistan.

\section{Materials and Methods}

\section{Study design}

A questionnaire-based descriptive cross-sectional study design was implemented to acquire the data from diabetes patients. The study was carried out between December 2015 and March 2016.

\section{Study site}

Southern Punjab was the study area selected for this study. This area was further divided into three cities: Bahawalpur, Multan, and Rahim Yar Khan. Bahawalpur accounted for $3.3 \%$ of the entire population of Punjab, Multan included $4.23 \%$ of total Punjab's population, and Rahim Yar Khan accommodated $4.26 \%$ of the overall provincial inhabitants ${ }^{19}$.

\section{Study samples and study settings}

All those who had been diagnosed as diabetics according to the measuring standards of the American Diabetes Association (taking diabetes medication for at least or more than a year) and were on oral hypoglycemic or insulin therapy regardless of any religion, gender, age, socioeconomic status, and willing to participate were recruited in the study. Both written and verbal consent was taken from every participant before initiation of the interview. Any private information such as name or contact was not requested purposefully. Recently diagnosed patients and patients not willing to participate or not capable to cope with the researcher (mentally compromised and unconscious) were waived off from the study. All primary health-care centers (PHCC) and private clinics in these target districts were noted and cataloged. Among all listed ones, 3 PHCC and three private clinics were selected. Clinics including diabetes management and family practice/general medicine/internal medicine and with the more patient flow were selected.

\section{Study sampling}

These targeted sites did not possess any type of diabetes registry or electronic catalogs for diabetic population, so systematic random sampling within these settings (centers/clinics) was chosen to recruit the 
patients for participation in the study. Thus, every $3^{\text {rd }}$ DM patient visiting selected PHCC and private clinics was approached. Of total approached patients, only 398 responded. 373 selected patients who were not willing to participate (either in a hurry or did not find benefit in the interview) and 129 patients who were mentally compromised or gravely ill were excluded from the study.

\section{Study instrument and study variables}

The questionnaire was divided into four sections. First part comprised of the demographic variables such as age, gender, locality, monthly income, marital status, educational level, height, and weight. Body mass index (BMI) was calculated by the standard method (weight in $\mathrm{kg}$, divided by the square of the height in $\mathrm{m}^{2}$ ). The categorization was done according to the following criteria: underweight $<18.5 \mathrm{~kg} / \mathrm{m}^{2}$, overweight 25.0 $29.9 \mathrm{~kg} / \mathrm{m}^{2}$, and obesity $\geq 30.0 \mathrm{~kg} / \mathrm{m}^{2}$. Furthermore, the $\mathrm{BGL}$ and cholesterol monitoring reports were also included in this part. BGL and cholesterol levels were analyzed at the time of the interview using a glucometer and a lipid analyzer. Patients were characterized as dyslipidemic if the total cholesterol was $>5.60 \mathrm{mmol} / \mathrm{L}$.

The second part of the questionnaire was related to diet history. The food items along with the quantity and frequency were measured and enumerated. This portion was open-ended, and patients were requested to remind as many food items as they could. The other factors which were part of this section were that either patient felt at ease with the diet plan or patient knew which diet is harmful to them, both of these questions were close ended, and patient has to answer in yes or no. To measure the diet compliance, the 3-day recall method was used for the dietary items (macronutrients), quantity, and frequency of meals. Scoring was done afterward and score of one was given if each dietary intake lies within the prescribed range of food (carbohydrate: $288 \mathrm{~g} \pm 10 \%$, fat: $52 \mathrm{~g} \pm 10 \%$, protein: $73 \mathrm{~g} \pm$ $10 \%$, fiber: $25 \mathrm{~g} \pm 10 \%$, or calorie: $1800 \mathrm{Kcal} \pm 10 \%$ ) or equivalent. If the carbohydrate intake of the patients was in the above-given range, he was given a positive score (1), and if the carbohydrate range is out of range mentioned above, then the patient is given 0 score, the same was with all other food items. Summarization of scores was carried out, and if the scores were above than $75 \%$, the patient was compliant ${ }^{20}$.

The third section of the questionnaire was related to the exercise compliance. At least $1 / 2 \mathrm{~h}$ rigorous walk/day, 5 days a week, or a total of $2.5 \mathrm{~h}$ exercise a week was set as minimum required standard for exercise compliance $^{21}$. The questions included in this sections were "do you at least perform $2.5 \mathrm{~h}$ exercise per week or 30 min per day?" and "do you believe that exercise will lead to weight loss?" Both the questions were close ended.

The fourth section was related to smoking habits. Those patients who reported smoking any cigarettes in any quantity in the past 12 months were regarded as current smoker ${ }^{22}$. The question asked in this sections was "did you smoke any kind of cigarette in the past 12 months?" and "did you face at least one episode of cardiovascular disease (CVD)." All the questions were close ended. The presence of CVD was confirmed if the patient had faced previous attacks of myocardial infarction (MI) or angina and was further verified by medical records.

This questionnaire initially was constructed in an English version following an extensive literature review. This was then translated into Urdu version for ease of acceptance. The English version is translated into Urdu and then back translated into an English version with the help of a person who spoke both languages.

\section{Ethical approval}

The Ethics Committee of Xi'an Jiaotong University Shaanxi, China, authorized the study for medical research. Furthermore, approval was taken from the Medical Superintendent of relevant hospitals and doctors of private clinics in writing. This study was conducted according to the tenets of Helsinki and having the ethical code of DIAB-17-23.

\section{Statistical analysis}

Data were thoroughly checked for the completeness and were manually cleaned. Careful entry of data into Epi data 3.1.0 was carried out and was cross-checked by colleague researchers. The SPSS for Windows, Version 18.0 (SPSS, Chicago, IL, USA) was used for the analysis of the data. Data were summarized by descriptive analysis. Percentages were used for definite variables, whereas continuous variables were articulated by mean \pm standard deviation (SD). The relationship among the proposed predictors and compliance to diet and exercise and relationship of predictors of smoking were evaluated by binary logistic regression. To determine variables independently associated with diet, exercise compliance, and smoking prevalence, variables with $p \leq 0.25$ in the bivariate analysis were selected for multivariable logistic 
regression. We base this on the Wald test from logistic regression and $p$ value cutoff point of 0.25 . More traditional levels such as 0.05 can fail in identifying variables known to be important ${ }^{23,24}$. Statistical significance of association among the variables was accessed using 95\% $\mathrm{Cl}$ with a respective odd ratio. $\mathrm{p} \leq 0.05$ was assumed as cutoff point to demonstrate statistically significant association. Correlation among the diet, exercise compliance, smoking, and BGL and cholesterol level were estimated using Spearman's rank correlation coefficient $(p<0.01)$ Correlation criteria are as follows: $>0.75$ excellent correlations, $0.5-0.75$ good correlation, $0.25-0.50$ fair correlation, and 0-0.25 weak correlation ${ }^{25}$.

\section{Data quality assurance}

To guarantee the quality of data, data collectors were endowed with appropriate training. A pre-check was also conducted on $5 \%$ of the total target population to ensure length, clarity, completeness, and consistency.

To sustain the quality of data, the prime investigator (PI) carried out regular checks, spot investigations, and reviewed finished questionnaire. Meanwhile, the PI harmonized the overall process. Appropriate training was provided to all data collectors and calibration was done after each measurement.

\section{Results}

\section{Demographic data}

A total of six sites were targeted in three selected districts, and 900 patients were approached while only 398 of them agreed to the interview. The response rate was $44.3 \%$, and only 299 of the respondents completed the questionnaire. Mean age \pm SD of the participants was a $48.8 \pm 14.6$ years with a minimum age of 8 years and maximum of 85 years. $169(56.5 \%)$ participants were males, 130 (43.5\%) were females, 270 (90.3\%) were married, and $29(9.7 \%)$ were single. Of 299 , $103(34.5 \%)$ were rural residents and 196 (65.5\%) were residents in urban areas. 124 (41.5\%) participants had their education under primary level, whereas 68 (22.7\%) of the study population had a monthly income lower than 15000 PKR (104 Pakistani Rupees (PKR) = 1 United States Dollar [USD]) (Table 1).

The mean duration \pm SD of disease was $9.36 \pm$ 6.9 years. Diabetes family history was positive in $204(68.2 \%)$. Most of the study population were in normal BMI range (64.2\%), while BGL was normal for
Table 1. Demographic characteristics of diabetic patients in Southern Punjab, Pakistan

\begin{tabular}{|l|c|}
\hline Demographic characteristics & $\begin{array}{c}\text { Respondents } \\
\text { N (\%) }\end{array}$ \\
\hline Age $(48.8 \pm 14.6)$ & $17(5.7)$ \\
$<25$ & $71(23.7)$ \\
$26-40$ & $116(38.7)$ \\
$41-55$ & $95(31.8)$ \\
$>55$ & \\
\hline Locality & $196(65.5)$ \\
Urban & $103(34.5)$ \\
\hline Rural & \\
\hline Gender & $169(56.5)$ \\
\hline Male & $130(43.5)$ \\
\hline Female & \\
\hline Monthly income (PKR) & $68(22.7)$ \\
\hline$<15000$ (< 145 USD) & $134(44.8)$ \\
\hline $15000-30000$ (145-290 USD) & $97(32.4)$ \\
\hline$>30000$ (> 290 USD) & \\
\hline Marital status & $270(90.3)$ \\
Married & $29(9.7)$ \\
\hline Single & \\
\hline Education & $124(41.5)$ \\
\hline Less than primary & $65(21.7)$ \\
\hline Primary-middle & $71(23.7)$ \\
\hline Secondary-high School & $39(13.1)$ \\
\hline Graduate & \\
\hline
\end{tabular}

PKR: Pakistani Rupees, USD: United States Dollar

$187(62.7 \%)$ and cholesterol level was normal in $180(60.8 \%)$ patients (Table 2).

\section{Dietary practice}

One hundred and nine (36.5\%) patients followed the diet plan according to specified criteria and showed diet compliance. The ratio of dietary compliance was slightly higher in males $(38.5 \%)$ than females $(33.8 \%)$. The good dietary practice was $38.8 \%$ in rural and $35.2 \%$ in the urban respondents. Similarly, diet compliance was confirmed by $40.5 \%$ of patients of age $41-55$ and $20 \%$ of patients above 55 years.

\section{Exercise compliance}

One hundred and seventy-six (58.8\%) respondents avowed that they do at least $2.5 \mathrm{~h}$ walk or equivalent work out per week. Males (60.3\%) were more prone to do physical activity than the females $(56.9 \%)$. The rural $(56.3 \%)$ population demonstrated slightly lower proportion of the exercise compliance than urban $(60.2 \%)$ residents. Almost two-third of married $(60.4 \%)$ and less than half of single $(44.8 \%)$ respondents were showing physical activity. 
Table 2. Clinical characteristics of diabetic patients in Southern Punjab, Pakistan

\begin{tabular}{|c|c|}
\hline Variable & $\mathbf{N}(\%)$ \\
\hline $\begin{array}{l}\text { Family history of diabetes } \\
\text { Positive } \\
\text { Negative }\end{array}$ & $\begin{array}{c}208(69.6) \\
91(30.4)\end{array}$ \\
\hline $\begin{array}{l}\text { Duration of diabetes (years) }(9.36 \pm 6.9) \\
\begin{array}{l}1-5 \\
6-10 \\
11-15 \\
>15\end{array}\end{array}$ & $\begin{array}{l}100(33.4) \\
109(36.5) \\
47(15.7) \\
43(14.4)\end{array}$ \\
\hline $\begin{array}{l}\text { Total cholesterol } \\
\text { High }(>5.60 \mathrm{mmol} / \mathrm{L}) \\
\text { Normal }(\leq 5.60 \mathrm{mmol} / \mathrm{L})\end{array}$ & $\begin{array}{l}116(39.2) \\
180(60.8)\end{array}$ \\
\hline $\begin{array}{l}\text { Body mass index } \\
\text { Underweight } \\
\text { Normal } \\
\text { Overweight }\end{array}$ & $\begin{array}{l}47(15.7) \\
192(64.2) \\
60(20.1)\end{array}$ \\
\hline $\begin{array}{l}\text { Blood glucose level } \\
\text { Normal }(<200 \mathrm{mg} / \mathrm{dl}) \\
\text { High (>200 mg/dl) }\end{array}$ & $\begin{array}{l}187(62.7) \\
111(37.3)\end{array}$ \\
\hline $\begin{array}{l}\text { Exercise compliance } \\
\text { Yes } \\
\text { No }\end{array}$ & $\begin{array}{l}176(58.9) \\
123(41.1)\end{array}$ \\
\hline $\begin{array}{l}\text { Diet compliance } \\
\text { Yes } \\
\text { No }\end{array}$ & $\begin{array}{l}109(36.5) \\
190(63.5)\end{array}$ \\
\hline $\begin{array}{l}\text { Smoker } \\
\text { Yes } \\
\text { No }\end{array}$ & $\begin{array}{c}46(15.4) \\
253(84.6)\end{array}$ \\
\hline
\end{tabular}

\section{Smoking prevalence}

Smoking prevalence was reported by 46 (15.4\%) patients. Of 169 males, 41 (24.2\%) were smokers, while among 130 females, 5 (3.8\%) were smokers. The prevalence of smoking among urban (16.8\%) residents was higher compared to rural (12.6\%).

\section{Factors related to diet, exercise compliance, and smoking}

Research for the association of predictor's of compliance was done using both univariate and multivariate analysis. Predictors which illustrated an association with compliance and smoking prevalence at $p \leq 0.25$ in the univariate analysis were elected as candidate variables in multivariable analysis. The variable which had the $p \leq 0.25$ in bivariate model for the diet compliance is age, knowledge of harmful diet, and feeling at ease with the diet plan. While age, marital status and belief that exercise will lead to weight loss were candidate variables for multivariate analysis for exercise compliance. Similarly, age and gender showed the significance level lower than 0.25 in bivariate analyses, so they were selected for the analysis in the multivariate logistic regression.

After adjusting all the relevant factors for the diet, exercise compliance and smoking in multivariate regression patients who felt easy with the diet plan were 20 times more likely to have diet compliance [adjusted odds ratio $(A O R)=20.87495 \%$ confidence interval $(\mathrm{Cl})=9.876,44.119 \mathrm{p}=0.00]$. Moreover, patients who knew what kind of diet was harmful to them showed 7 times more diet compliance $(\mathrm{AOR}=7.106,95 \% \mathrm{Cl}=$ $3.529,14.309 p=0.00)$. There was a decrease in exercise compliance $(\mathrm{AOR}=0.971,95 \% \mathrm{Cl}=0.951,0.991)$ with an increase in age. Patients who believed that the exercise would lead to weight loss were almost 5 times more physically active as compared to others (AOR = $4.978,95 \% \mathrm{Cl}=2.725,9.093, \mathrm{p}=0.00$ ). Similarly, in case of smoking, females had $12.7 \%$ probability to be smoker as compared to men (AOR $=0.127,95 \% \mathrm{Cl}=$ $0.048,0.331, p=0.00$ ). The results of the multivariate analysis are shown in table 3 (in a separate file).

\section{Correlation of diet, exercise compliance, and smoking with BGL and cholesterol}

The results of the correlation between the variables are shown in table 4. There was an insignificant negative correlation between the diet compliance and BGL. The insignificant positive linear correlation was present between exercise compliance, smoking, and BGL. Similarly, insignificant negative correlation was seen between diet compliance and cholesterol and exercise compliance and cholesterol level, and positive insignificant relationship existed between the smoking and cholesterol level.

\section{Discussion}

In this cross-sectional study, we were able to demonstrate the proportion of diet compliance, exercise compliance, smoking prevalence, and factors affecting all the previously mentioned variables in the diabetic population in Southern Punjab, Pakistan. The outcomes of our research activity indicated the overall poor dietary compliance and merely $36.5 \%$ population were up to right dietary practice. Feeling at ease with 


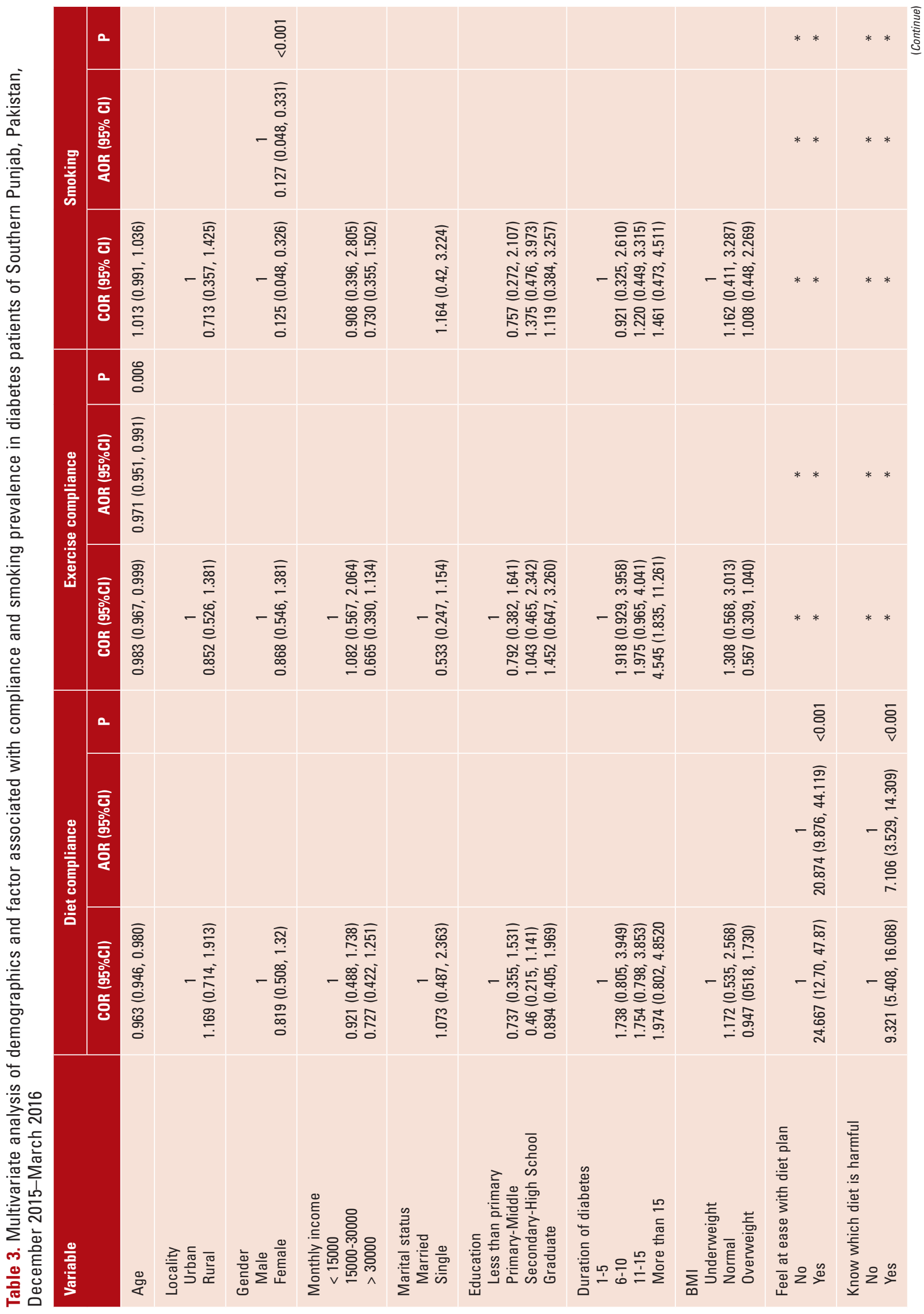




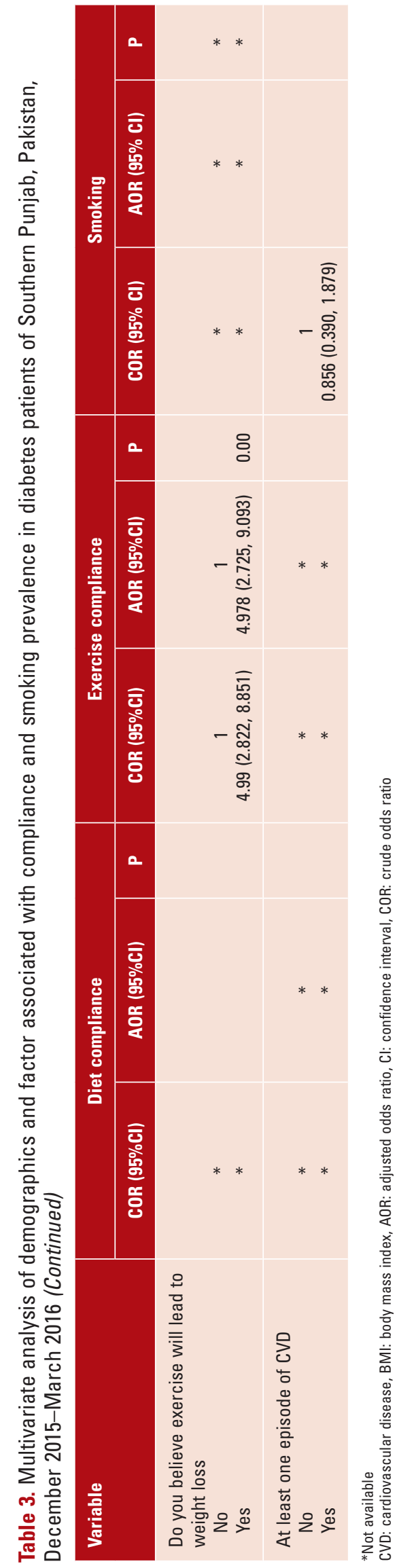

diet plan and knowledge about the harmful food items were recognized as variables which were notably associated with good dietary compliance. Almost two-thirds $(63.5 \%)$ of the diabetic patient in Southern Punjab were showing poor diet management. Previous studies conducted to evaluate the diet compliance in Riyadh, Saudi Arabia, and the United Arab Emirates also demonstrated the poor dietary compliance ${ }^{26,27}$. These two results despite the variation in study settings, socioeconomic differences, and variation in types of food were in accordance with the previous results. Similarly, the findings of our study are in accordance with the previous results from Calgary ${ }^{28}$ (poor compliance $55 \%$ ), Texas, ${ }^{29}$ and Kuwait ${ }^{30}$. Another study executed among diabetic patients in Medical College Hospital, Addis Ababa, Ethiopia, also verified poor dietary practice which also concords our study ${ }^{31}$. Lack of awareness about the unsafe diet can be attributed to poor education about diabetic nutrition in the community and hospital settings. Patients with poor knowledge about the detrimental diet showed poor dietary practice which is also shown in the previous studies in Malaysia ${ }^{32}$. Similarly, our findings proved that those patients who felt at ease with the planned diet adhered to it. No previous results strengthen this fact. However, the possible reason is that those patients who had psychologically accepted the importance of diet on disease management are good in following the dietary practice. Further, research activities are required to explore psychological barriers to diet compliance.

Our study furthermore demonstrated poor exercise compliance in $41.2 \%$ of patients. These results were in line with the results of the previous study conducted in $\mathrm{Nepal}^{20}$, whereas our results opposed the results of a study in which $33 \%$ of respondents said that they were indulged in physical activity ${ }^{33}$. The disparity may be due to different parameters for measuring the compliance. Moreover, our research also pointed out that patients who believe that exercise will lead to weight loss were significantly more compliant to physical activity. This type of behavioral investigation was not done in the previous studies. As the correlation existed between the weight loss and exercise, thus we investigated the belief that either patient believed that exercise could lead to weight loss.

We further succeeded in estimating the smoking prevalence among the population studied. Our study unravels the fact that $15.3 \%$ of the patients included are current smokers. The occurrence of smoking in our study is almost the same as recorded previously in 
Table 4. Correlation between the variables

\begin{tabular}{|l|c|c|c|c|c|c|}
\hline \multirow{2}{*}{ Variables } & \multicolumn{2}{|c|}{ Diet compliance } & Exercise compliance & \multicolumn{3}{c|}{ Smoking } \\
\cline { 2 - 7 } & r & p & r & p & r & p \\
\hline Blood glucose level & -0.0091 & 0.882 & 0.11 & 0.057 & 0.043 & 0.456 \\
\hline Cholesterol level & -0.033 & 0.567 & -0.064 & 0.269 & 0.076 & 0.193 \\
\hline
\end{tabular}

Pakistan $(13 \%)^{17}$, whereas estimated prevalence is lower than the previously evaluated smoking prevalence in Pakistan (27\%) and Japan (35\%) ${ }^{34,35}$. Another study conducted in the USA evaluated the prevalence of the smoking which is $2.7 \%$ in 10 -14-year-old patients, $17.1 \%$ in 15-19-year-old patients, and $34.0 \%$ in $\geq 20$ patients $^{36}$. These results are dissimilar to our results. Results of our study showed high smoking prevalence as compared to smoking prevalence in non-diabetics in Malaysia $(11.9 \%)^{37}$. Our results depicted significant association of gender with smoking prevalence, which also have been documented ${ }^{34}$. In the current study, females have $0.127(\mathrm{AOR}=0.127,95 \% \mathrm{Cl}=0.048,0.331)$ more chances of being smoker which is entirely in line with the results from the non-diabetic population in Malaysia ${ }^{37}$.

Our study follows some limitations. First, the population involved consisted of some pediatric patients and these patients when interrogated about the belief and feeling ease with the diet plan, could not interpret the results accurately. The first of kin is asked about the information which may lack clarity and validity and might leave ambiguity. However, very limited number of our population is in this range, so it is not a problem. Second, the comparisons of the smoking, exercise compliance, and diet compliance were made against the $B G L$ which is not the parameter used to represent the disease management outcome. HBA1c comparisons instead provide the proper understanding of one's disease management. However, facilities and resources did not allow calculating the HBA1c measurements, so the previous comparisons were made.

\section{Conclusion}

A considerable amount of the study population is showing poor diet compliance, but obedience to physical activity is much improved. Health educationists, dietitian's clinicians, and policymakers should be cluedup about the alarming situation of non-compliance about physical activity and diet in diabetic patients in developing countries such as Mexico and Pakistan. Similar results are observed in developing and developed countries so, to deal with these problems, the prime focus should be the proper delivery of the diabetes management knowledge. Large-scale education campaigns should be started to make the patient realize the value of diet modifications and exercise. Large-scale activities should be designed mainly of prospective nature to estimate the determinants of diet and exercise compliance.

\section{Ethical disclosures}

Protection of human and animal subjects. The authors declare that the procedures followed were in accordance with the regulations of the relevant clinical research ethics committee and with those of the Code of Ethics of the World Medical Association (Declaration of Helsinki).

Confidentiality of data. The authors declare that no patient data appear in this article.

Right to privacy and informed consent. The authors declare that no patient data appear in this article.

\section{Conflict of interest}

The author declared no conflict of interest.

\section{Funding}

This work was funded by "Young Talent Support Program" of Xian Jiaotong University and China Medical Board (Grant No. 16-262).

\section{Authors' contributions}

Ali Hassan Gillani designed the questionnaire and study protocol. Abu Bakar Ahmad, Sadia Bashir, and Ali Hassan Gillani conducted the study. Mohamed 


\section{Izham Mohamed Ibrahim revised the manuscript Yu Fang supervised the whole study.}

\section{References}

1. About Diabetes. International Diabetes Federation Web site. Available from: http://www.idf.org/about-diabetes Published 2013. [Last accessed on 2017 Mar 05]

2. Non-communicable disease. World Health Organization. Available from http://www.who.int/mediacenter/factsheet/fs355/en/index.html Published [Last accessed on 2016 Sep27].

3. International Diabetes Federation. IDF Diabetes Atlas. $6^{\text {th }}$ ed; 2015. Available from: http://www.idf.org/sites/default/files/Atlas-poster-2015 EN.pdf. [Last accessed on 2016 Feb 13

4. Diabetes in Pakistan. Available from: http://www.idf.org/membership/ mena/pakistan. [Last accessed on 2016 Sep 28

5. Cardiac Disease in Pakistan. Available from: http://www.shifa.com.pk chronic-disease-pakistan. [Last accessed on 2016 Oct 03]

6. Mannapur BS, Selvan VT, Dorle AS, et al. A case series study on compliance and its influencing factors among Type II diabetes mellitus patients attending a tertiary healthcare centre at Bagalkot District, Karnataka. Ann Community Health. 2016;4:7-13.

7. Ekore RI, Ajayi IO, Ekore JO. Dietary management of diabetes: a practical approach for primary care physicians in Nigeria. Diabetes. 2008;16:13-4

8. Centers for Disease Control and Prevention (CDC), and Centers for Disease Control and Prevention (CDC). National diabetes fact sheet: national estimates and general information on diabetes and pre diabetes in the United States, 2011. Atlanta, GA: US Department of Health and Human Services, Centers for Disease Control and Prevention; 2011. p. 201

9. Shamsi N, Shehab Z, AlNahash Z, AlMuhanadi S, Al-Nasir F. Factors influencing dietary practice among type 2 diabetics. Bahrain Med Bull. 2013:35

10. Association Sad. South African diabetes association. In South africa diabetes association; 2001.

11. Zinman B, Ruderman N, Campaigne BN, Devlin JT, Schneider SH, American Diabetes Association. Physical activity/exercise and diabetes mellitus, position statement. Diabetes Care. 2003;26:1.

12. Marwick TH, Hordern MD, Miller $T$, et al. Exercise training for type 2 diabetes mellitus. Circulation. 2009;119:3244-62.

13. Knowler WC, Barrett-Connor E, Fowler SE, et al. Reduction in the incidence of type 2 diabetes with lifestyle intervention or metformin. $\mathrm{N}$ Engl J Med 2002:346:393-403.

14. Kowall B, Rathmann W, Strassburger K, et al. Association of passive and active smoking with incident type 2 diabetes mellitus in the elderly population: the KORA S4/F4 cohort study. Eur J Epidemiol. 2010;25:393-402.

15. Willi C, Bodenmann P, Ghali WA, Faris PD, Cornuz J. Active smoking and the risk of type 2 diabetes: a sysmetic review and meta-analysis JAMA. 2007:298:2654-64

16. Shaikh AN, Bhatty S, Baloch AA, et al. Prevalence and pattern of tobacco use in diabetic patients at Civil Hospital Karachi. Pak J Chest Med. Available from: http//www.pjcm.net/html-v14-n4-ab3.php. Published 2010. [Last accessed on 2017 Jun 20.

17. Khuwaja AK, Lalani S, Azam IS, Ali BS, Jabbar A, Dhanani R. Cardiovascular disease-related lifestyle factors among people with Type 2 diabetes in Pakistan: a multicenter study for the prevalence, clustering, and associated socio demographic determinants. Cardiol Res Pract. 2011;2011:656835

18. Tuomilehto J, Lindström J, Eriksson JG, et al. Prevention of type 2 diabetes mellitus by changes in lifestyle among subjects with impaired glucose tolerance. N Engl J Med. 2001;344:1343-50.
19. Population of Pakistan. Available from: http://www.pbs.gov.pk/sites/default/files/other/pocket_book2006/2.pdf. [Last accessed on 2017 Mar 06].

20. Parajuli J, Saleh F, Thapa N, Ali L. Factors associated with non adherence to diet and physical activity among Nepalese type 2 diabetes patients; a cross sectional study. BMC Res Notes. 2014;7:1.

21. US Department of Health and Human Services, Public Health Service, National Institutes of Health, National Heart, Lung, and Blood Institute. Third Report of the National Cholesterol Education Program (NCEP) Expert Panel on Detection, Evaluation, and Treatment of High blood Cholesterol in Adults (Adult Treatment Panel III): Final report. Circulation. 2002;106:3143-54

22. Yusuf $\mathrm{S}$, Hawken $\mathrm{S}$, Ounpuu $\mathrm{T}$, et al. Effect of potentially modifiable risk factors associated with myocardial infarction in 52 countries (the INTERHEART study): case control study. Lancet. 2004;364:937-52.

23. Arega Sadore A, Abebe Gebretsadik L, Aman Hussen M. Compliance with iron-folate supplement and associated factors among antenatal care attendant mothers in Misha district, south Ethiopia: community based cross-sectional study. J Environ Public Health. 2015;2015:781973.

24. Burgess $S$. Identifying the odds ratio estimated by a two stage instrumental variable analysis with a logistic regression model. Stat Med. 2013;32:4726-47.

25. Cohen J. In: Hillsdale NJ, editor. Statistical Power Analysis for the Behavioral Sciences. $2^{\text {nd }}$ ed. New Jersey: Lawrence Erlbaum; 1988.

26. Al-Kaabi J, Al-Maskari F, Saadi H, Afandi B, Parkar H, Nagelkerke N. Assessment of dietary practice among diabetic patients in the United Arab Emirates. Rev Diabet Stud. 2008;5:110-5.

27. Mohamed BA, Almajwal AM, Saeed AA, et al. Dietary practices among patients with type 2 diabetes in Riyadh, Saudi Arabia. J Food A Gric Environ. 2013;11:110-4.

28. Rowley C. Factors Influencing Treatment Adherence in Diabetes. Universiy of Calgary; 1999. Available from: http://www.who.int/features/factfiles/ diabetes/01_en.html. [Last cited on 2017 Mar 07].

29. Waldo AL. Noncompliance in Patients with Type 2 Diabetes Enrolled in Local Diabetes Education Program. Vol. 18. City of Laredo health department. Laredo, Texas: Spring 2008. p. 85-6.

30. Serour M, Alqhenaei H, Al-Saqabi S, Mustafa AR, Ben-Nakhi A. Cultural factors and patients' adherence to lifestyle measures. Br J Gen Pract. 2007;57:291-5.

31. Worku A, Abebe SM, Wassie MM. Dietary practice and associated factors among Type 2 diabetic patients: a cross sectional hospital based study, Addis Ababa, Ethiopia. Springer Plus. 2015;4:15.

32. Tan MY, Magarey JM, Chee SS, Lee LF, Tan MH. A brief structured education programmed enhances self-care practices and improves glycaemic control in Malaysians with poorly controlled diabetes. Health Educ Res. 2011;26:896-907

33. Thomas N, Alder E, Leese GP. Barriers to physical activity in patients with diabetes. Postgrad Med J. 2004;80:287-91.

34. Khalid N, Khan EA, Saleem S, Tahir A, Mahmood H, Saleem S. Prevalence and associated factors of cigarette smoking among type 2 diabetes patients in Pakistan. Int $\mathrm{J}$ Collab Res Internal Med Public Health. 2014;6:73-88

35. Ito $\mathrm{H}$, Antoku $\mathrm{S}$, Furusho $\mathrm{M}$, et al. The prevalence of the risk factors for atherosclerosis among type 2 diabetic patients is greater in the progressive stages of chronic kidney disease. Nephron Extra. 2013;3:66-72.

36. Reynolds K, Liese AD, Anderson AM, et al. Prevalence of tobacco use and association between cardio metabolic risk factors and cigarette smoking in youth with type 1 or type 2 diabetes mellitus. J Pediatr. 2011;158:594-601.

37. Lim KH, Jasvindar $\mathrm{K}$, Cheong SM, et al. Prevalence of smoking and its associated factors with smoking among elderly smokers in Malaysia: findings from a nationwide population-based study. Tob Induc Dis. 2016;14:8. 